International Journal Of Mechanical Engineering And Information Technology

\title{
A Survey of Awareness about Security in E-payment System
}

\author{
Author \\ Deepak Mathur \\ Lachoo Memorial College of Science \& Technology (Autonomous), Jodhpur \\ Email- mathur.deepak25@gmail.com
}

\begin{abstract}
E-commerce provides the capability of buying and selling products, information and services on the Internet. In an ecommerce environment, payments take the form of money exchange in an electronic form, and are therefore called Electronic Payment. E-Payment system is secure, there should be no threat to the user credit card number, smart card or other personal detail, payment can be carried out without involvement of third party, It makes E payment at any time through the internet directly to the transfer settlement and form E-business environment. Studied have been carried out on E-Payment system. An efficient payments system reduces the cost of exchanging goods and services, and is indispensable to the functioning of the interbank, money, and capital markets. Questions are related to EPayment systems in which given options are agree, disagree, strongly disagree, and strongly agree, Neutral. After analysis and comparison of various modes of electronic payment systems, it is revealed that it is quite difficult, if not impossible, to suggest that which payment system is best. Some systems are quite similar, and differ only in some minor details. Thus there are number of factors which affect the usage of e-commerce payment systems.

Keywords:Credit card, Debit card, Digital Wallet, E-cheque, Smart Card, E-cash.
\end{abstract}

\section{INTRODUCTION}

Internet growth has gave birth to e-commerce. Ecommerce is a system used by organizations to sell products and services online or over the internet. ${ }^{1}$ Physical cash and e-payment are different kind of methods for payment. The growth of $\mathrm{E}$ commerce made e-payment a convenient mode of exchanging goods and services. This resulted from the growth of the internet and Electronic commerce. Epayment is a system that uses secure electronic transaction between organizations and individuals. Epayment systems were not introduced to replace cash but as a better alternative to cash and barter trade. Though, there have been great utilization of e-payment facility in general, the use of e-payment is quite low. Fear, lack of knowledge is the main reason behind to not adopting e-payment amongst users. At the same time for those who are using, how much is the awareness about the proper use of the technology, is also matter of concern. Their ignorance or lack of awareness can judge about the risk they have in using this technology.Electronic payment systems are generally classified into four categories: credit card and debit cards, smart card, electronic cheque, and electronic cash.

\section{REVIEW OF LITERATURE}

Electronic payment systems uses internet connectivity to process transactions. ${ }^{2}$.E-payment system in India, has shown tremendous growth, but still there has lot to be done to increase its usage. Still $90 \%$ of the transactions are cash based. So, there is a need to widen the scope of electronic payment. Innovation, incentive, customer convenience and legal framework are the four factors which contribute to strengthen the Epayment system. $^{3}$

Eben discussed about the impact of information security for e-business with emphasis on the security threats and potential losses that could arise from those vulnerabilities. E-business security is analyzed as consisting of 6 dimensions: confidentiality, integrity, availability, legitimate use, auditing and nonrepudiation. This paper has proposed that designing a comprehensive and systematic security policy is a need for implementing-business security. ${ }^{4}$

Cheng, Hamid and Cheng ${ }^{5}$ suggested five perceived risks. Physical, performance, psychological, financial and time loss". Physical risk was then described as a cashless or card loss , Performance indicates a risk that gains additional charges when utilized, Psychological risk was examined as a risk that if a mode of payment 
is made will affect the perceived image of the user, Time loss risk means it will take more of the time than the alternative mode of payment and finally financial risk which was described as loss meaning if the mode of payment that if used will cause financial loss and might not be refundable or reversible.

Srinivasan ${ }^{6}$ stated that success of an e-business rests on many factors. He defined trust is something that an ebusiness must strive to achieve over a period of time. The author suggested some contributing factors for gaining customer trust are: appeal of the Web site, product or service offerings, branding, quality of service and trusted seals. Trust can be viewed from many angles such as transaction, information content, product, technology and institution. This paper analyses the role of trust from the transaction perspective and highlights the things that an e-business could do for building customer trust. Factors contributing to trust are not easy to measure. It is developed over time. People trust a business based on their own past experience as well as by third party recommendations. He concluded that the e-businesses are accessible from anywhere at any time, there are additional impediments in building and maintaining trust. The limitation of this paper is that it did not focus much on how a company can enhance the security when doing online commerce.

ToñitaPerea Y Monsuwé et.al.proposed a framework to increase researchers' understanding of consumers" attitudes toward online shopping in US and Europe and their intention to shop on the Internet. The framework uses the constructs of the Technology Acceptance Model (TAM) as a basis, extended by exogenous factors and applies it to the online shopping context. The review shows that attitudes toward online shopping and intention to shop online are not only affected by ease of use, usefulness, and enjoyment, but also by exogenous factors like consumer traits, situational factors, product characteristics, previous online shopping experiences, and trust in online shopping. ${ }^{7}$

Abdul Naveed Tariq et.al.conducted a study on -Assessing the impact of trust and security factors on consumers' willingness for online shopping among the urban Moroccans. This study attempts to examine the customers' willingness to shop online by taking into account demographic factors as well as trust and security-related factors. A logistics regression analysis was demonstrated and the findings indicate that the customers' willingness to shop online is explained by age, trust, security, awareness and piracy factors. The findings of the study also indicates that majority of the respondents intend to shop online. The research outcomes are undoubtedly useful for both the government and online vendors for better understanding online shoppers. The study also facilitates policy-makers to set and develop a better online shopping infrastructure with the technological competitive advantage for both online vendors and consumers. $^{8}$

Baten and Kamil determined the economic prospects of ebanking as well as demonstrating the scope and benefits of e-payments in Bangladesh. ${ }^{9}$ Salehi and Alipour examined e-banking and e-payments in an emerging economy seeking to provide empirical evidence from Iran. ${ }^{10}$ James used Statistical Package for Social Sciences (SPSS) to investigate the acceptance of E-banking in Nigeria. The result shows that acceptance of is significantly influenced by Age, Educational Background, Income, Perceived Benefits, Perceived Ease of Use, Perceived Risk and Perceived Enjoyment. ${ }^{11}$

\section{RESEARCH METHODOLOGY}

A descriptive survey research method was used for this study. Data was collected using structured questionnaire, the questionnaire consisted of three sections, that is- Section A, B and C. The first section is to collect demographic information to compare and analyse subgroups. The second section is concerned about methods and devices used for e-payment systems. Third section is related to the risk, trust, convenience, and awareness perception among use of e-payment by users. The relevant data was collected on 68 questions based on various aspects related to epayment system. 384 respondents participated in the survey. The data was collected through Google forms.

The data was then examined using statistical techniques of analysis such as frequencies and percentages for the descriptive part of the study. They were used to determine the percentage of respondents for each of the variables tested. The analysis further involved correlations and statistical significance of the findings. The findings were presented through figures and tables.

\subsection{Demography}

Out of 384 samples 165 were females and 219 were males. Major chunk of the users of e-payment system was below 40 years of age. It is interesting to note here 


\section{IJMEIT// Vol.05 Issue 03//March//Page No: 1846-1850//ISSN-2348-196x}

that between the age of 30 to 40 years, males and females are same.

\begin{tabular}{|l|l|l|l|}
\hline Age_Group & Female & Male & Total \\
\hline $20-<30$ & 84 & 119 & 203 \\
\hline $30-<40$ & 60 & 67 & 127 \\
\hline $40-<50$ & 18 & 23 & 41 \\
\hline $50-<60$ & 3 & 6 & 9 \\
\hline $60-<70$ & 0 & 4 & 4 \\
\hline TOTAL & 165 & 219 & 384 \\
\hline
\end{tabular}

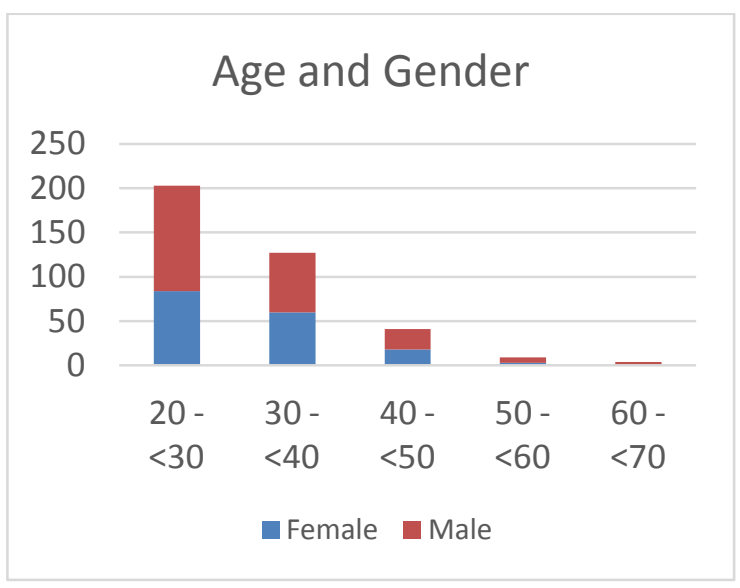

\subsection{Use of device for e-payment}

Laptops and mobiles are used mostly for the purpose of e-payments. Desktop usage are comparatively quite low.

\begin{tabular}{|l|l|l|l|}
\hline Education & desktop & laptop & mobile \\
\hline Secondary & 9 & 26 & 23 \\
\hline Sr Secondary & 11 & 30 & 19 \\
\hline Graduate & 18 & 53 & 51 \\
\hline Post Graduate & 21 & 51 & 72 \\
\hline
\end{tabular}

\section{Devices used for e-payment}

Post Graduate

Graduate

Sr Secondary

Secondary

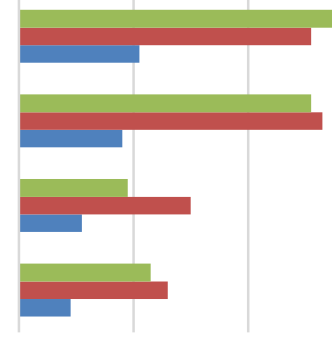

$\begin{array}{ccccc}0 & 20 & 40 & 60 & 80 \\ \text { mobile } & \text { — laptop } & \text { q desktop }\end{array}$

\subsection{Length of Password}

More than half of the users have password for internet payments is of length 6 characters. Only 33.5 percent users have password of more than 7 characters. 35 percent of the users have password of 6 characters. Only 9 percent users have used special characters in their passwords.

\begin{tabular}{|l|l|l|l|l|l|l|}
\hline Education & $\begin{array}{l}4 \\
\text { chars }\end{array}$ & $\begin{array}{l}5 \\
\text { chars }\end{array}$ & $\begin{array}{l}6 \\
\text { chars }\end{array}$ & $\begin{array}{l}7 \\
\text { chars }\end{array}$ & $\begin{array}{l}8 \\
\text { chars }\end{array}$ & $\begin{array}{l}>8 \\
\text { chars }\end{array}$ \\
\hline Secondary & 5.2 & 34.5 & 24.1 & 12.1 & 15.5 & 8.6 \\
\hline SrSecondary & 21.7 & 23.3 & 33.3 & 10.0 & 10.0 & 1.7 \\
\hline Graduate & 5.7 & 22.1 & 41.8 & 6.6 & 11.5 & 12.3 \\
\hline Post Graduate & 5.6 & 24.3 & 36.8 & 9.7 & 10.4 & 13.2 \\
\hline
\end{tabular}

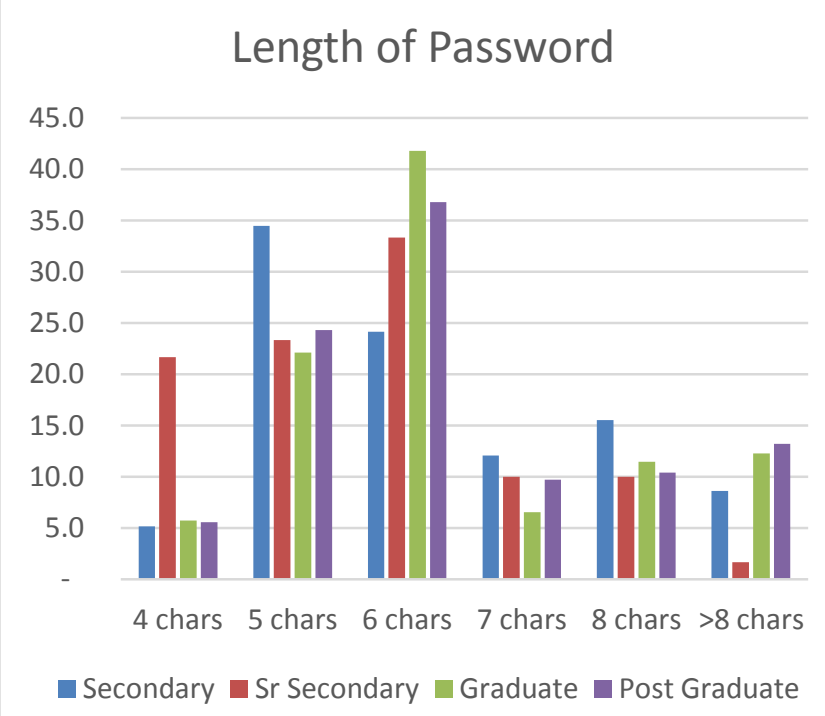

\subsection{Change of Password}

Password change for the e-payment websites.

\begin{tabular}{|l|l|l|l|}
\hline Education & 1 Month & 4 Months & Never \\
\hline Secondary & $25.86 \%$ & $51.72 \%$ & $22.41 \%$ \\
\hline Sr Secondary & $31.67 \%$ & $61.67 \%$ & $6.67 \%$ \\
\hline Graduation & $29.51 \%$ & $62.30 \%$ & $8.20 \%$ \\
\hline PG & $31.94 \%$ & $64.58 \%$ & $3.47 \%$ \\
\hline
\end{tabular}

Change of Password and Educational Qualification

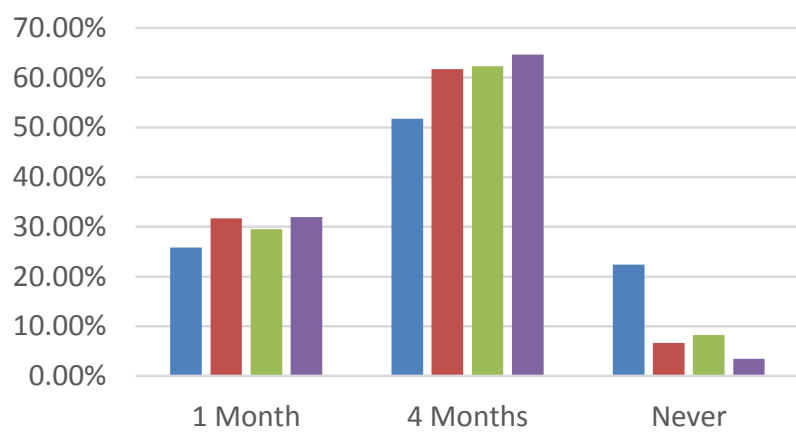

- Secondary Sr Secondary Graduation a PG 


\begin{tabular}{|l|l|l|l|}
\hline Age & 1 Month & 4 Months & Never \\
\hline $20-<30$ & $56.65 \%$ & $37.44 \%$ & $5.91 \%$ \\
\hline $30-<40$ & $55.12 \%$ & $35.43 \%$ & $9.45 \%$ \\
\hline $40-<50$ & $24.39 \%$ & $68.29 \%$ & $7.32 \%$ \\
\hline $50-<60$ & $11.11 \%$ & $22.22 \%$ & $66.67 \%$ \\
\hline $60-<70$ & $0.00 \%$ & $0.00 \%$ & $100.00 \%$ \\
\hline
\end{tabular}

\section{Change of Password and Age}

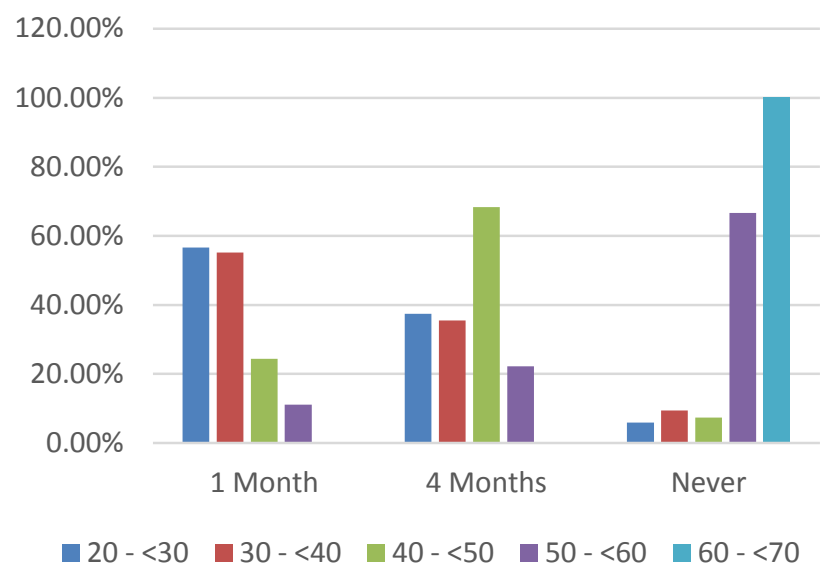

\subsection{Use of Antivirus / Firewall}

Only 15.1percent of users have purchased any antivirus software. Around 24 percent users have some or other antivirus/firewall software installed. Majority $60.9 \%$ of the users are not using any such safety measure. Interestingly, all of them were aware about the importance of antivirus software.

\begin{tabular}{|l|l|}
\hline Antivirus/firewall & Percent \\
\hline Purchased & $15.10 \%$ \\
\hline Free & $23.96 \%$ \\
\hline No such software & $60.94 \%$ \\
\hline
\end{tabular}

\section{Antivirus / Firewall}

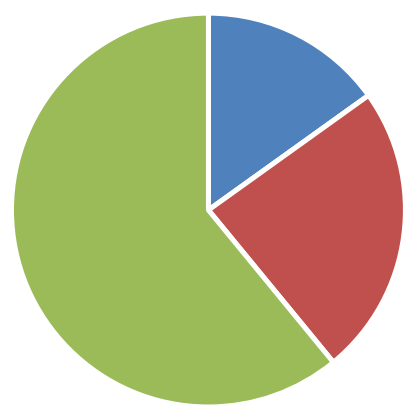

घ Purchased - Free - No such software
3.6 Logging out the banking website / Closing the app

Around 45 percent of the users said that they make sure to logout the banking website when they finish their task when they are using it on laptop or desktop. About closing the app on mobile, most of the users were ignorant of this action, and said they don't do it.

\subsection{Number of Accounts}

289 users have more than one bank accounts, and out of these 289, 145 have more than one online bank account. 92 of these are having different passwords for their accounts. Rest 53 are using one password for their different accounts.

\section{CONCLUSION}

Technology has arguably made our lives easier. One of the technological innovations in banking, finance and commerce is the Electronic Payment. It provides greater freedom to individuals in paying The study reveals that the peoples are not so aware about the security concerns while making e-payments. There is a need to have awareness programs by the various agencies in this regard.

\section{REFERENCES}

1. Nyamiaka, S. D., Effects of e-payment on operational risk management: a case of private universities in Kenya. 2015

2. Olawepo, G. T. and Akanbi, P. A., An empirical investigation into factors influencing the adoption of internet banking among undergraduate students in Nigeria. International journal of research in commerce \& management, No.5, 2010

3. Okediran. A biometric identification based scheme for secured E-payment. Computation in biosciences and engineering, 1 (2): 5, 2013

4. EbenOtuteye, A Systematic Approach to EBusiness Security, Faculty of Administration, University of New Brunswick, Fredericton, Canada, 2003

5. Cheng, A. y., Hamid, N. R. A. and Cheng, E. H. Risk perception of the E-payment systems: a young adult perspective. 7, 2009.

6. S. Srinivasan, Role of trust in e-business success, Information Management \& Computer Security, Vol. 12 Iss: 1, pp.66 - 72, 2013 
7. ToñitaPerea y Monsuwé, Benedict G.C. Dellaert, Ko de Ruyter, What drives consumers to shop online? A literature review, International Journal of Service Industry Management, Vol. 15 Iss: 1, pp.102 - 121, 2004

8. Abdul Naveed Tariq, BadrEddaoudi, Assessing the impact of trust and security factors on consumers' willingness for online shopping among the urban Moroccans, International Journal of Business \& Management Science, Vol.2, Issue 1, pp. 1732, 2009

9. MA Baten, AA Kamil, E-banking of economical prospects in Bangladesh, Journal of Internet Banking and Commerce 15 (2), 110., 2010

10. Mahdi Salehi, MehrdadAlipour, E-Banking in Emerging Economy: Empirical Evidence of Iran, International Journal of Economics and Finance, Vol 2, No 1, 2010

11. James A. Odumeru, The Acceptance of Ebanking by Customers in Nigeria, World Review of Business Research Vol. 2. No. 2.. Pp. $62-74,2012$ 